\title{
Fibro-osseous Lesions in the Maxillofacial Region
}

\author{
Taranjit Kaur
}

Fibro-ossoeus lesions have posed a diagnostic dilemma since the beginning, when first case was reported in late 19th century. Since then various lesions are included in this group, yet the understanding of the lesions remains obscure for the clinican/surgeon. The main reason for this, is their histological resemblance with one another, where they all show varying degrees of healthy bone replaced by fibrous tissue and some amount of bone/cementum like tissue intermingled in between. This chapter is written with the aim of simplifying these group of bony lesions for its readers and highlighting the key idea of interdisciplinary approach in the management of these lesions where the oral pathologist along with radiologist and clinician play a pivotal role in differentially diagnosing these lesions, for the maxillofacial surgeon to chose and perform her/his duty of managing them, rightfully, for their patients. The spectrum of these lesions have seen several changes during the course of history yet there is still ample scope for ambiguity in identification and classification of the lesions, hence the authors have chosen few most commonly encountered lesions in Indian subcontinent, for the description and discussion.

\subsection{Introduction}

Fibro-osseous lesions (FOLs) are miscellaneous and challenging group of intra-osseous lesions posing a diagnostic dilemma for the clinician as well as the pathologist and this makes them interesting to treat and manage for the surgeon [1]. It was Boyko who first reported a case of craniofacial fibrous dysplasia, diagnosed at that time as osteofibroma, in

Electronic Supplementary Material The online version of this chapter (https://doi.org/10.1007/978-981-15-1346-6_30) contains supplementary material, which is available to authorized users.

T. Kaur $(\bowtie)$

Department of Oral and Maxillofacial Surgery, Government Dental College and Hospital, Jamnagar, Gujarat, India
1936, which was called leontiasis ossea, the term first described by Virchow in 1862, for bony lesions involving upper facial bones resulting in lion-like faces. Clinicians and pathologists have gone through a drastic change in their understanding of these lesions since then yet pathogenesis and progression still needs further investigation [2].

One thing that is common in all these lesions is that normal bone is replaced by connective tissue and fibroblasts; occasional foci of mineralisation is seen, with varying degrees of bone- or cementum-like tissue. The biological behaviour of these lesions ranges from benign and indolent to aggressive, inflammatory and neoplastic [1].

The diagnosis is difficult to obtain on the basis of histopathology alone, clinical history and radiographic details have an important role to play in the decision-making of the management. Most often than not, pathologists may not be able to comment more than just benign fibro-osseous lesion in the absence of additional clinical and radiographic information [1].

Though considered as one of the most confusing and challenging pathological processes, it was the meticulous hard work of Charles A Waldron, an American Oral Pathologist, who was first to describe these lesions in a systematic way and propose the classification, in the year 1985, which was later revised by himself in the year 1993 [3, 4].

With the evolution of technology and a better clinical understanding of the lesions as well as the availability of ample literature, various other classifications have emerged from time to time $[5,6]$.

\subsection{Classifications}

Fibro-osseous lesions have undergone a turbulent phase with regard to its classification and categorisation and in this chapter, it may not be possible to include all the available classifications, but the major ones have been referred to. The major changes in classifications are seen in the publications by Waldron [5], Waldron [6], Slootweg [7], WHO [8], Speight 
and Carlos [9] and Eversole et al. [1]. As all the changes in classifications have not been included in the chapter, readers are encouraged to refer the concerned publications. Some of the commonly used classifications are as follows.

\subsubsection{Waldron's Classification, $1985[5,10]$}

1. Fibrous dysplasia (FD)

(a) Monostotic

(b) Polyostotic

2. Fibro-osseous (cemental) lesions' plausible origin in the periodontal ligament

(a) Periapical cemental dysplasia

(b) Localised fibro-osseous-cemental lesions (presumably reactive in nature)

(c) Florid cemento-osseous dysplasia (gigantiform cementoma)

(d) Ossifying and cementifying fibroma

3. Fibro-osseous neoplasms of uncertain or detectable relationship to those arising in the periodontal ligament

(a) Cementoblastoma, osteoblastoma and osteoid osteoma.

(b) Juvenile active-ossifying fibroma and other so called aggressive-ossifying/cementifying fibromas.

\subsubsection{WHO Classification of FOLs, 2005 [8]}

At the core of these classifications is the spectrum of clinicopathological entities in which the diagnosis can only be made by the correlation of clinical, radiological and histological features.

1. Ossifying fibroma (OF)

2. Fibrous dysplasia

3. Osseous dysplasia

(a) Periapical osseous dysplasia

(b) Focal osseous dysplasia

(c) Florid osseous dysplasia

(d) Familial gigantiform cementoma

4. Central giant cell granuloma

5. Cherubism

6. Aneurysmal bone cyst

7. Solitary bone cyst

\subsubsection{Speight and Carlos Classification (2006) [9]}

1. Fibrous Dysplasia

(a) Monostotic FD

(b) Polyostotic FD

(c) Craniofacial FD
2. Osseous Dysplasia
(a) Periapical Osseous Dysplasia
(b) Focal Osseous Dysplasia
(c) Florid Osseous Dysplasia
(d) Familial Gigantiform Cementoma

3. Ossifying Fibroma
(a) Conventional Ossifying Fibroma
(b) Juvenile Trabecular-Ossifying Fibroma
(c) Juvenile Psammomatoid-Ossifying Fibroma

\subsubsection{Eversole Classification, 2008 [1]}

In 2008, Eversole et al. gave a comprehensive classification by including developmental lesions, neoplastic lesions and inflammatory/reactive processes. This classification emphasised that final diagnosis can be attained by the correlation of microscopy, imaging and clinical features together and not on the basis of histopathological features alone.

1. Bone dysplasias

(a) Fibrous dysplasia

(i) Monostotic

(ii) Polyostotic

(iii) Polyostotic with endocrinopathy (McCune-Albright)

(iv) Osteofibrous dysplasia

(b) Osteitis deformans or Pagets disease

(c) Pagetoid heritable bone dysplasias of childhood

(d) Segmental odontomaxillary dysplasia

2. Cemento-osseous dysplasias

(a) Focal cemento-osseous dysplasia

(b) Florid cemento-osseous dysplasia

3. Inflammatory/reactive processes

(a) Focal sclerosing osteomyelitis

(b) Diffuse sclerosing osteomyelitis

(c) Proliferative periostitis

4. Metabolic disease

(a) Hyperparathyroidism

5. Neoplastic lesions (ossifying fibromas)

(a) Ossifying fibroma

(b) Hyperparathyroidism jaw lesion syndrome

(c) Juvenile-ossifying fibroma

(i) Trabecular type

(ii) Psammomatoid type

(d) Gigantiform cementomas

Based on the above-mentioned classification systems, author have selected few most commonly occurring BFOLs (Benign fibro-osseous lesions), which will allow a better understanding of these lesions, from a maxillofacial surgeon's point of view.

It is apparent from this wide spectrum of FOL that a diagnosis cannot be made from pathology reports alone and it has 
to be correlated with the clinical and radiological findings [11]. BFOL form a wide spectrum of diseases, which occur intra-osseously and is characterised by similar microscopic pictures with hypercellular fibroblastic stroma and varying amounts of bone, cementum and other calcified structures. El Mofty stated that reactive, dysplastic, developmental and neoplastic processes are included under the broad umbrella of BFOLs and the treatment given varies from case to case [12].

\subsection{Fibrous Dysplasia (FD)}

Fibrous Dysplasia is a benign dysplastic disease with a wellapproved genetic cause in GNAS 1 (Guanine nucleotidebinding protein alpha-stimulating activity polypeptide 1) gene. The clinical severity of the disease depends on the stage of foetal life (prenatal/postnatal) at which gene mutation occurs. So far, the identification of GNAS1 mutations are the most useful molecular tool to differentiate fibrous dysplasia from other fibro-osseous lesions [13].

\subsubsection{Clinical Features}

There are four main clinical subtypes of FD depending on the time of mutation in GNAS 1

(a) Monostotic FD, which affects single bone: Post-natal life mutation.

(b) Polyostotic FD affecting multiple bones at the same time: Mutation in the late embryonic stages of life.

(c) McCune-Albright syndrome in which multiple bony lesions are seen along with skin pigmentations and endocrinopathies presenting itself as precocious puberty and hyperthyroidism: Due to mutation in early embryonic stages of life.

(d) Craniofacial FD confined to bones of craniofacial complex.

Craniofacial variant will be discussed in detail, as it is the most common FD encountered in the maxillofacial region.

FD is the disease of growing bones and the majority of lesions are diagnosed in first two decades of life, without any predilection for gender or race. Though mandibular lesions are purely monostotic, but the lesions involving maxilla, which invariably involve zygoma, sphenoid and other adjoining bones of the craniofacial skeleton, are not truly monostotic and hence may be suitably referred to as Craniofacial FD. Since multiple adjoining bones are involved of the same anatomic region, term polyostotic is avoided. Craniofacial FD appears in few commonly seen patterns,

One, involving maxilla-zygoma-sphenoid-frontal-nasal bones. Another, involving frontal-temporal-sphenoid-zygoma bones
Clinically, painless expansion of the affected area with facial asymmetry is the common presentation of FD. Rarely does a lesion expand the bone to cause structural weakening. Thickening of the skull bones and obliteration of the foramina of the base of the skull occasionally can present variously as headache, proptosis, visual loss, anosmia and hearing loss.

\subsubsection{Radiographic Features}

Radiographic features vary depending on the stage at which the lesion is diagnosed. Early onset lesions appear radiolucent and later as they age, the classical 'ground glass appearance' (Fig. 30.1) is the identifying feature.

The lesion is ill defined and is radiologically imperceptible from the adjoining normal bone. Ground glass appearance is due to radiodensity caused by abundance of woven bone, which also leads to fuzziness of the boundaries, and strict delineation of lesion from the normal bone is difficult on the radiograph. Poorly defined borders are the diagnostic clue for FD and also differentiate it from Ossifying fibroma, which has well-defined appearance on the radiograph. Publications have stressed on the importance of CT and CBCT as investigative modalities of FOLs [14].

The clinical case scenarios 1 and 2 are provided for the readers to appreciate the difference in the $\mathrm{CT}$ images between early and long-standing lesions

\section{Clinical case scenario 1 (Fig. 30.2a-e)}

A 17-year-old male with noted swelling in the upper right maxilla posterior vestibule region and he was aware of the swelling for about 1 month.

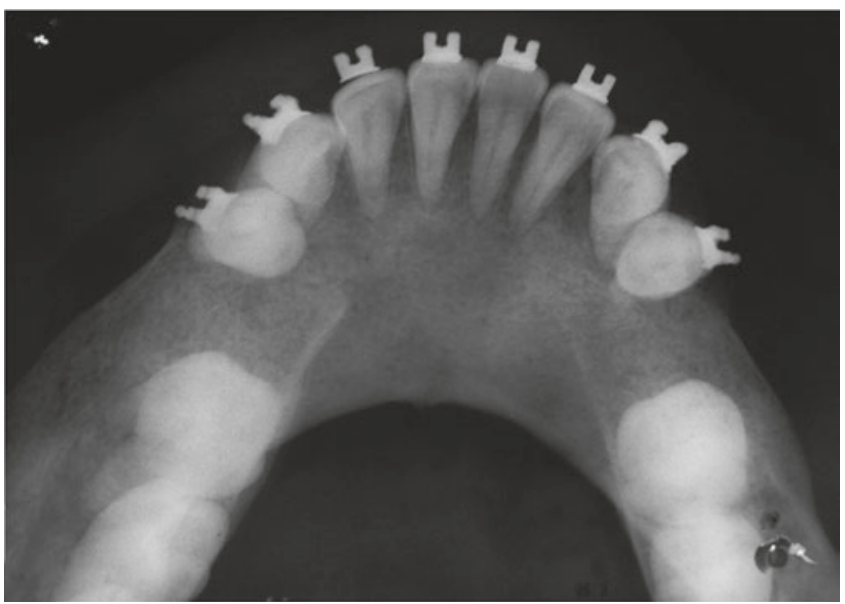

CAssociation of Oral and Maxillofacial Surgeons of India

Fig. 30.1 Occlusal image showing ground glass appearance in a 36-year-old female, who had aymptomatic bilateral body region mandible swelling 

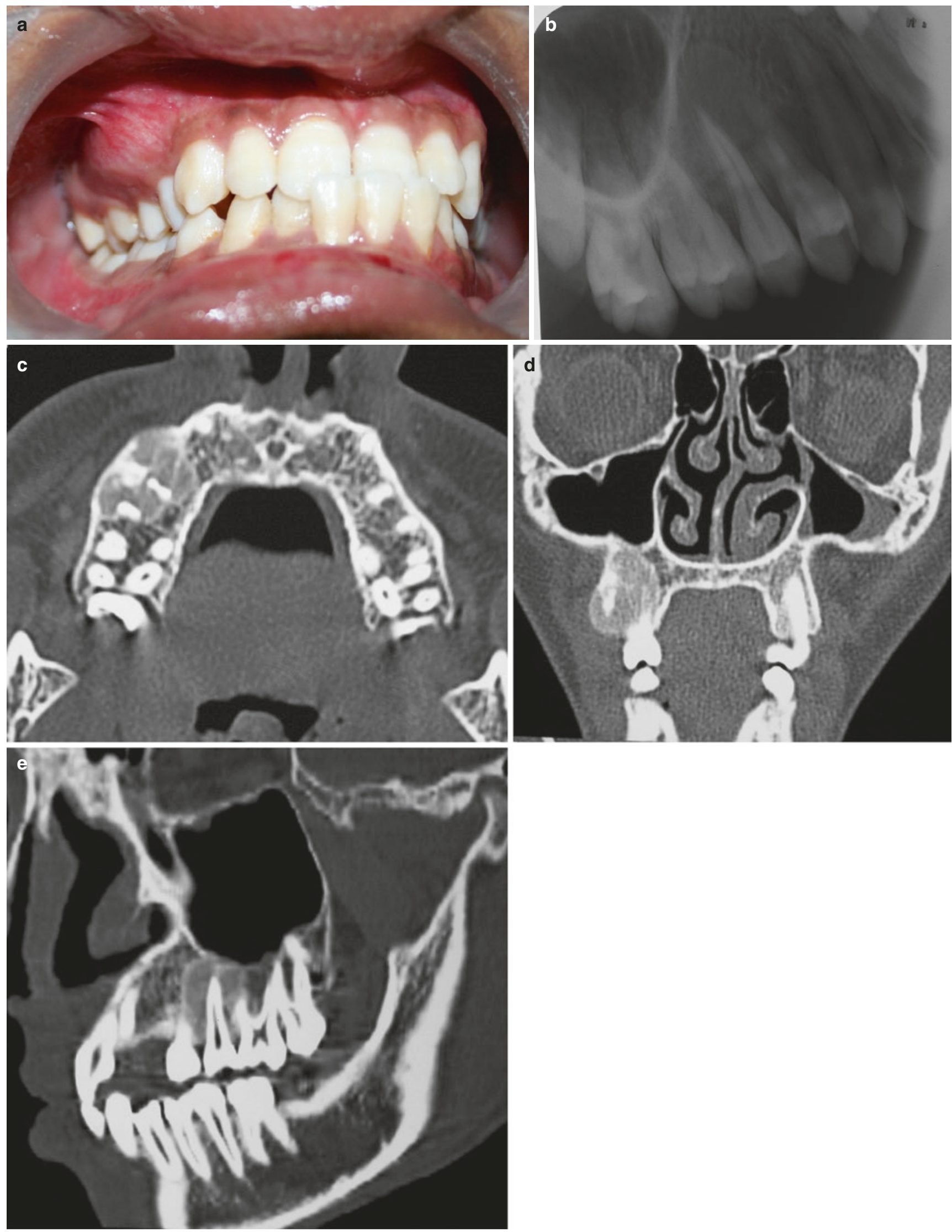

CAssociation of Oral and Maxillofacial Surgeons of India

Fig. 30.2 (a) Clinical picture of FD right upper posterior buccal sulcus. (b) Occlusal view showing ground glass appearance, no root resoprtion, no root displacement, hazy margins, lamina dura appeared to be lost in IOPA. (c) Axial view CT. (d) Coronal view CT. (e) Sagittal view CT 

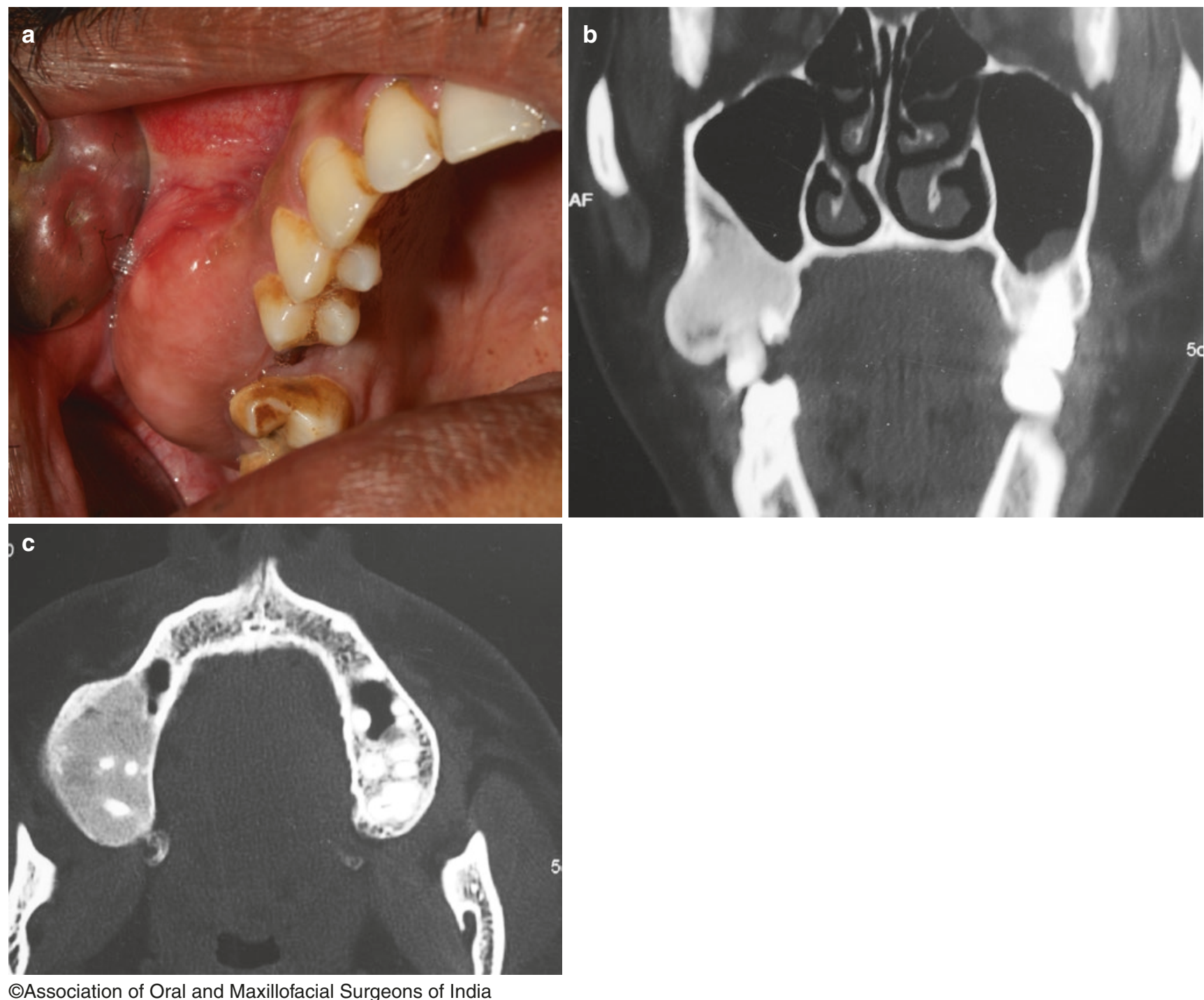

Fig. 30.3 (a) Clinical image. (b) Coronal CT showing more dense/opaque appearance of the lesion. (c) Axial image

Clinically, the lesion was Ovoid, well defined, non-tender and firm with no palatal expansion, involving the buccal suclus of tooth 13-16 (Fig. 30.2a).

Occlusal X-ray showed ground glass appearance (Fig. 30.2b), There was no root resorption, no root tilting, margins were hazy and lamina dura lost.

CT scan shows well-defined lesion (Fig. 30.3c-e-axial, coronal and sagittal views, respectively).

The Calcium and Phosphorous values were normal.

A bone incision biopsy was done and the final diagnosis was that FD. It was decided to observe the lesion till growth is completed; however, the patient was lost for follow up

Clinical case scenario 2 (Fig. 30.3a-c)

This patient in his late thirties was aware of the swelling on the right posterior upper jaw for past 5-6 years. After an initial biopsy proved it to be FD, the lesion was excised completely under GA.

\subsubsection{Histological Features}

Histologically, FD shows irregularly shaped trabeculae of immature woven bone dispersed in cellular fibroblastic stroma. The bone trabeculae evolve directly from stroma and assume delicate curvilinear patterns, which appear like 'Chinese letters' [15]. The osteoid is generally not rimmed with osteoblasts and develops into lamellar bone as the lesion matures. Such may not be the case with extra gnathic lesions.

\subsubsection{Treatment and Prognosis}

In a large majority of cases, lesions show the tendency of slow growth and eventually stabilise with the cessation of the growth phase. Indications for surgical treatment include functional deficits or significant cosmetic deformity. The aim of treatment is to restore function and cosmetic symmetry. 
The involvement of the bone may range from minimal to functional and/or esthetic deformity being present. Based on patient's age, the presence/absence of cosmetic and functional deficits and the growth rate, the treatment is currently designed in the following way [16] (Video 30.1).

1. Observation

2. Conservative approach in the form of surgical recontouring and reshaping.

3. Radical surgical approach involving resection and reconstruction.

In the case of minimal involvement, no surgical intervention may be needed but when involvement is more significant, surface shaving of excess bone, for cosmetic reasons may be done. Radical surgical approach is preferred in the case of significant functional and aesthetic deficit.

A treatment scheme offered by Chen in 1990 [17] is helpful in determining the approach depending on the extent of conditions. The lesions are defined as per the regions, in Zone 1, i.e. frontomaxillofacial are, it is advised that they are completely excised and reconstructed henceforth. In Zone 2, i.e. hair-bearing cranium, observation and conservative or radical approach as and when needed. Whereas in Zone 3, which is central cranial base, more conservative or observational approach is required due to the difficult location of neurovascular bundle, lastly Zone 4 lesions involving dentate maxilla and mandible are advised conservative treatment in the form of surgical recontouring and shaping. Optic canal decompression was advised on patients with orbital dysplasia and decreasing visual acuity.

Riclade in 2001 in his review article stated that in craniofacial dysplasia, early treatment is advised in progressive sensory disturbances, in order to reduce the problems caused by decompression at a later stage [18].

Non-surgical treatment has a limited role, radiotherapy is contraindicated. Steroids show some effectiveness in reducing bone pain and temporary relief from symptoms due to nerve compression. Calcitonin and pamidronate have shown some promise in recent studies but the results of long term trials are awaited [16].

Monostotic lesions of the craniofacial complex need to be differentiated from other FOLs like cemento-ossifying fibroma (COF) and diffuse-sclerosing osteomyelitis of the mandible [15] while COF most commonly appears in young adults in tooth bearing areas of mandible and maxilla, it is well defined and can be separated or scooped out from the adjoining healthy bone easily.

Clinical case scenario 3 is a 14-year-old boy who reported with a recurrent lesion on upper left buccal posterior alveo- lus. The clinical, radiological and surgical findings were suggestive of a COF; however, the pathology report was that of FD. This case is shown to highlight the varied pathology reports, which can be expected in dealing with lesions under the BFOL spectrum (Fig. 30.4a-d).

Clinical case scenario 4 (Fig. $30.5 \mathrm{a}-\mathrm{c}$ ) is given to show lesion, which had initial differential diagnosis of FD, but pathology report showed it to be sclerosing osteomyelitis

In 2008, eversole classification inflammatory reactive process containing focal sclerosing osteomyeliotis/diffuse sclerosing osteomyelitis (DSOM) and proliferative periostitis were categorised under BFOL.

Figure 30.6 is an OPG of a 11-year-old child who presented with recurrent pain and swelling left side body mandible. OPG shows a diffuse ground glass appearance, with changes in the trabecular pattern on the whole of the left ramus and body mandible. A provisional diagnosis of DSOM can be made. Unfortunately, the patient didn't report for further investigations. OPG is included to demonstrate the alteration of the trabecular pattern.

\subsection{Ossifying Fibroma/Cementifying Fibroma/Cemento-Ossifying Fibroma (COF) and Juvenile (Aggressive)- Ossifying Fibroma}

\subsubsection{Clinical Features}

These were traditionally a group of Fibro-osseous lesions with neoplastic tendencies. COF has had its own share of controversies, being included previously under BFOLs. The recent update in 2018; however, accepts COF as odontogenic in origin and had been placed under mesenchymal odontogenic tumours [19]. Another entity with a similar clinical picture is central odontogenic fibroma, which is also under benign mesenchymal tumours. Lesion that produces cementum including COF and cementoblastoma, thus, currently has found a new place.

In 2017, the consensus group felt that the term cementoossifying fibroma is suitably descriptive and indicates that these lesions are specific to the tooth-bearing areas of the jaws and can be distinguished from the two juvenile variants of ossifying fibroma. This clearly distinguishes it from ossifying fibromas that are non-odontogenic and are classified under benign fibro- and chondro-osseous lesions. The three variants are, therefore, defined as cemento-ossifying fibroma, juvenile trabecular-ossifying fibroma and juvenile psammomatoid-ossifying fibroma [20-22].

COF progressive painless buccal and lingual plate expansion. COF affects dentate segment of mandible and maxilla. 

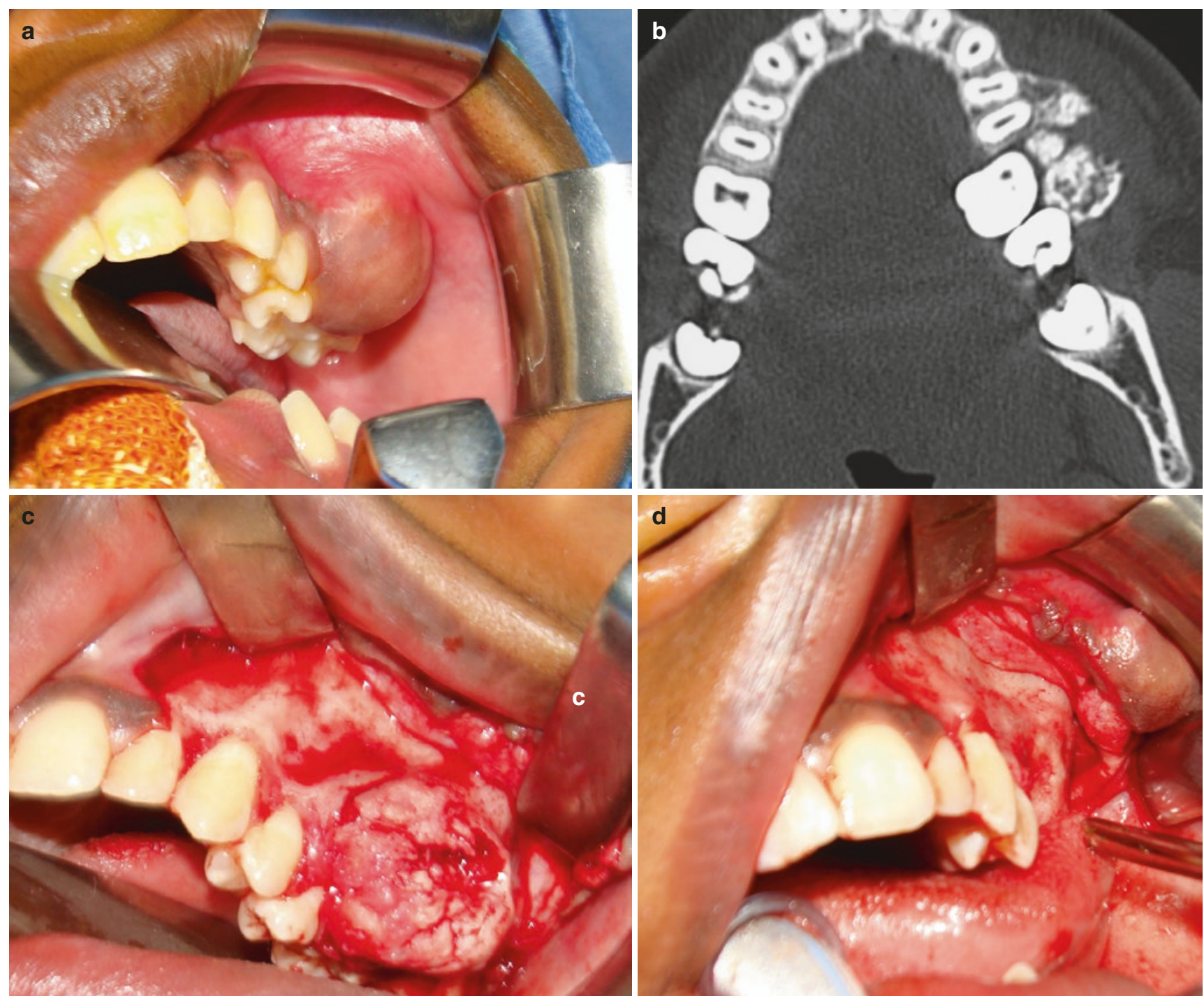

CAssociation of Oral and Maxillofacial Surgeons of India

Fig. 30.4 (a) Clinical image of swelling left upper buccal alveolus in a 14-year-old boy. (b) Axial CT image showing flecks of radiopacities. (c) Shows the lesion exposed, note the gritty nature, which could be easily shelled out with relative ease, in this case. (d) Intra-operative image where the lesion was shaved out from the alveolar bone via a mucoperiosteal flap approach
They are slow growing in nature in adults, but show aggressiveness in the younger age group. The teeth are generally displaced. Ossifying Fibromas demonstrate a well delineated or encapsulated cellular fibrous connective tissue with varying amounts of osseous products like bone and cementum (spherical calcification).

Lesions are more commonly seen in mandible (77\%) especially the molar region and are found exclusively in jaws. The peak age is 3rd and 4th decades of life and very strong female pre-dilection (almost 5:1). The juvenile variant (Juvenile-Ossifying Fibroma), which is also more aggressive, is seen in the younger age group [23].

\subsubsection{Radiological Features}

It is a well-demarcated radiolucent lesion, in the initial stages, separated from the surrounding healthy bone. Usually, a solitary lesion and is unilocular. The well-demarcated radiolucent/radiopaque appearance is the main differentiating consideration with Fibrous Dysplasia. Appearance is dependent on the maturity of the lesion, i.e. purely radiolucent (initial stages); mixed with radiopaque foci or radiopaque. The radiographic presentation of bowing of mandible with thinning and weakening of the lower border, particularly in large expansive lesions, is seen. Resorption or divergence of roots may result due to continued growth. 

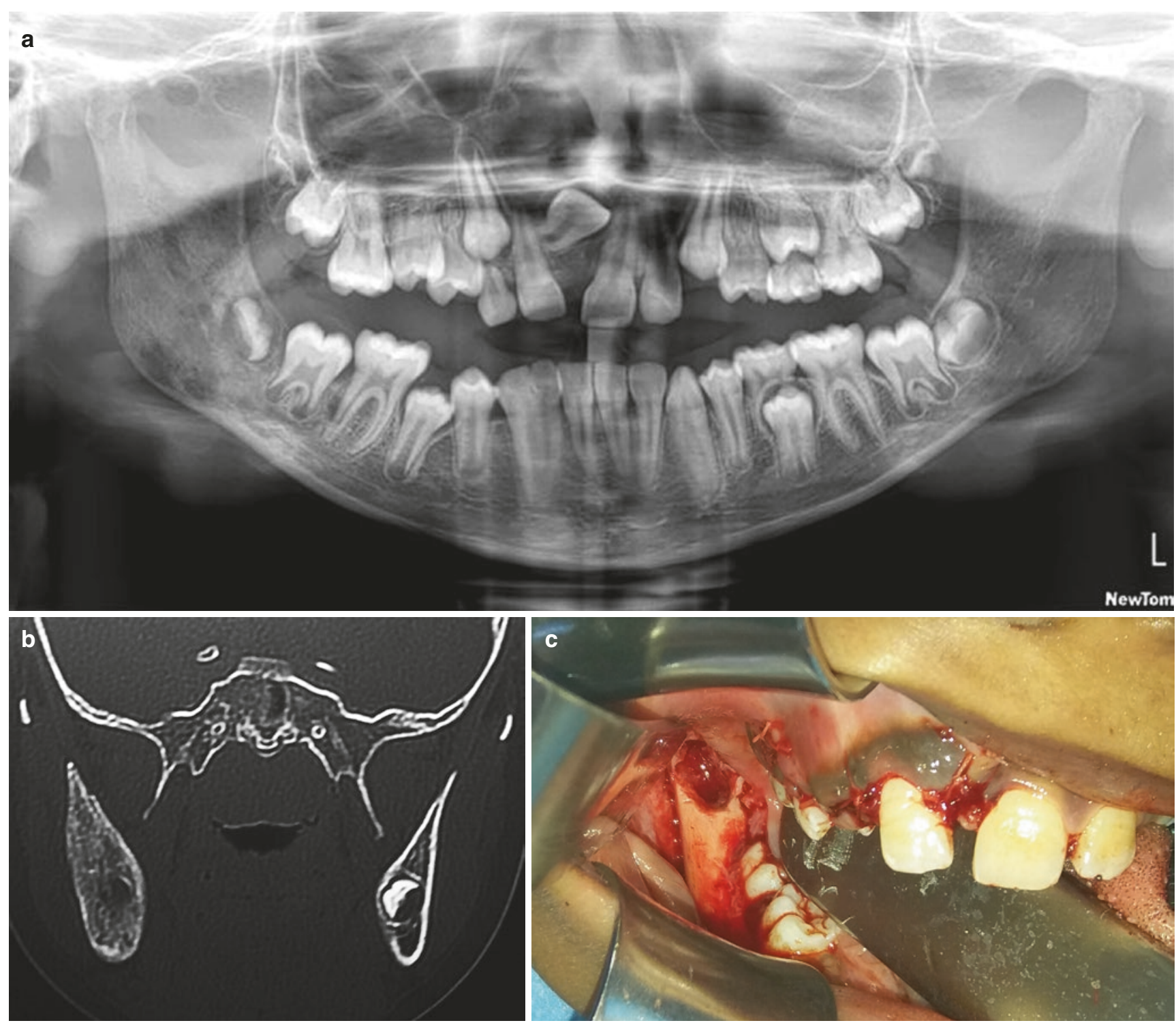

CAssociation of Oral and Maxillofacial Surgeons of India

Fig. 30.5 (a, b) OPG ant coronal CT cuts show evident changes in the right ramus of a 10-year-old girl, who presented with progressing facial asymmetry on the right side ramus region. The provisional diagnosis was of FD, but the bone biopsy (c) report was suggestive of sclerosing osteomyelitis

\subsubsection{Histologic Features}

Ossifying fibromas of craniofacial skeleton are divided into two categories depending on the cell of origin.

(A) Cemento-ossifying Fibroma (COF): OF with odontogenic origin.

(B) Juvenile (aggressive)-Ossifying Fibroma [9, 24-26]: subcategorised as (Table 30.1) (Fig 30.7)

1. Juvenile trabecular-Ossifying Fibroma (JTOF)

2. Juvenile Psammomatoid-ossifying fibroma (JPOF)

\subsubsection{Treatment and Prognosis}

COF is a slowly growing benign neoplasm commonly seen in the 3rd to 4th decades of life, if left untreated can enlarge to a significant size. Since it is radiographically as well as microscopically well circumscribed and shells out from the surrounding bone with little effort, it is curettage or enucleation a preferred initial treatment option. An important feature is, it is well defined and can be easily shelled out from the adjoining normal bone, grossly the lesion can be separated out in one piece or a few large chunks. The recurrence rate is variable and unpredictable. Surgical curettage is an 
Fig. 30.6 OPG in a

11-year-old child showing the diffuse change in the trabecular pattern at the left body/ramus region of mandible

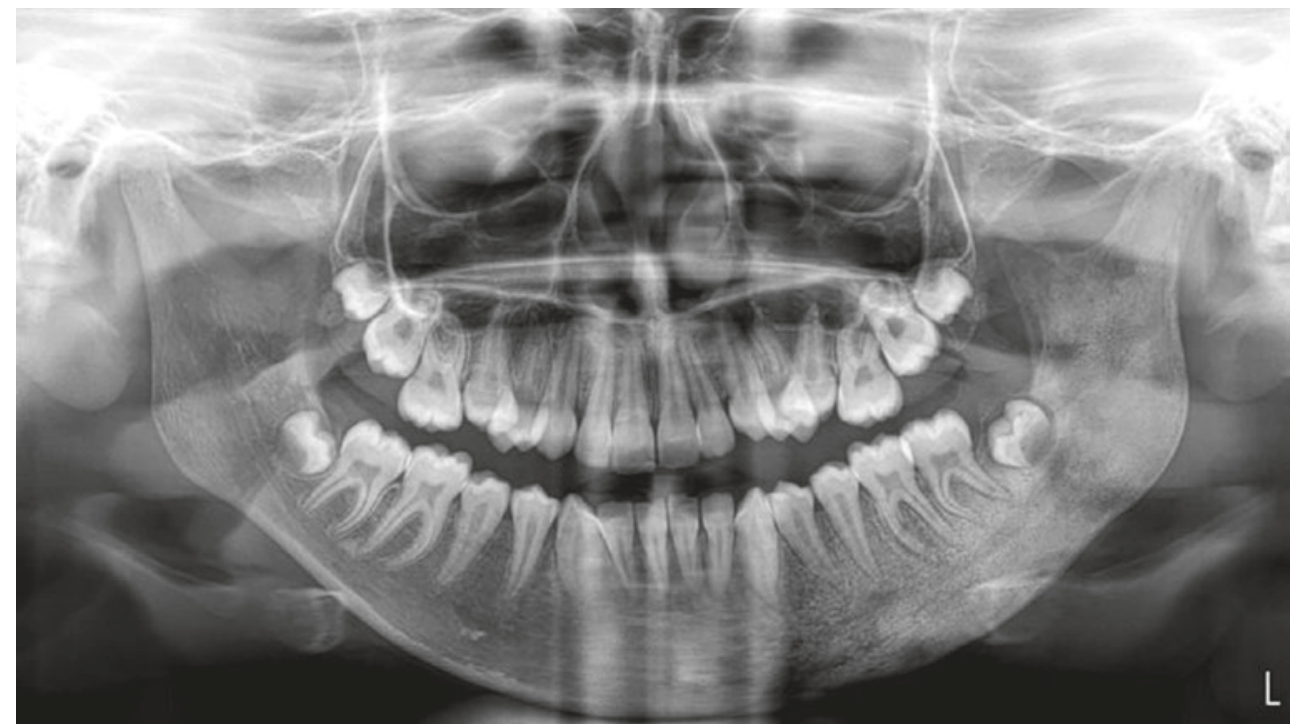

CAssociation of Oral and Maxillofacial Surgeons of India

Table 30.1 Comparing the main features of JTOF and JPOF (adapted from Speight and Carlos [9])

\begin{tabular}{|c|c|c|}
\hline & JTOF & JPOF \\
\hline Age ( mean) & $2-30$ years $(10)$ & 3 months -72 years $(20)$ \\
\hline Female: male & $1.2: 1$ & $1.3: 1$ \\
\hline site & $\begin{array}{l}\text { Maxilla 50\% } \\
\text { Mandible 44\% } \\
\text { Sino-nasal 6\% }\end{array}$ & $\begin{array}{l}\text { Sino-nasal } 62 \% \\
\text { Maxilla } 20 \% \\
\text { Mandible ramus } 10 \% \\
\text { Cranium } 8 \%\end{array}$ \\
\hline Radiology & $\begin{array}{l}\text { Well circumscribed } \\
\text { Speckled calcifications }\end{array}$ & $\begin{array}{l}\text { Well circumscribed, } \\
\text { aggressive, expands and } \\
\text { occupies the paranasal } \\
\text { sinuses }\end{array}$ \\
\hline Histopathology & $\begin{array}{l}\text { Densely cellular, } \\
\text { immature bone and } \\
\text { osteoid in a trabecular } \\
\text { pattern, osteoblast } \\
\text { rimming seen }\end{array}$ & $\begin{array}{l}\text { Densely cellular, } \\
\text { spherical cementum-like } \\
\text { psammomatoid } \\
\text { calcifications }\end{array}$ \\
\hline $\begin{array}{l}\text { Clinical } \\
\text { features }\end{array}$ & $\begin{array}{l}\text { Progressive and rapid } \\
\text { expansion of lesion, } \\
\text { pain may not be } \\
\text { present, in maxilla can } \\
\text { produce nasal } \\
\text { obstruction and } \\
\text { epistaxis }\end{array}$ & $\begin{array}{l}\text { Affects predominantly } \\
\text { extragnathic bones of } \\
\text { craniofacial skeleton, } \\
\text { particularly the paranasal, } \\
\text { orbital, frontal and } \\
\text { ethmoid bones. } \\
\text { Orbital extension of } \\
\text { sino-nasal tumors may } \\
\text { present as proptosis, } \\
\text { visual complaints nasal } \\
\text { stuffiness etc }\end{array}$ \\
\hline
\end{tabular}

acceptable trteatment [27]. Lesions exhibiting more aggressive behaviour and recurrence may need to undergo resection. The anatomical location and age of the patient and aggressiveness of the lesion have a role in deciding the treatment modality of the lesion.

Clinical case scenario 5 (a case of $\mathrm{COF}$ affecting the right side body of the mandible) (Fig. 30.8a-e).
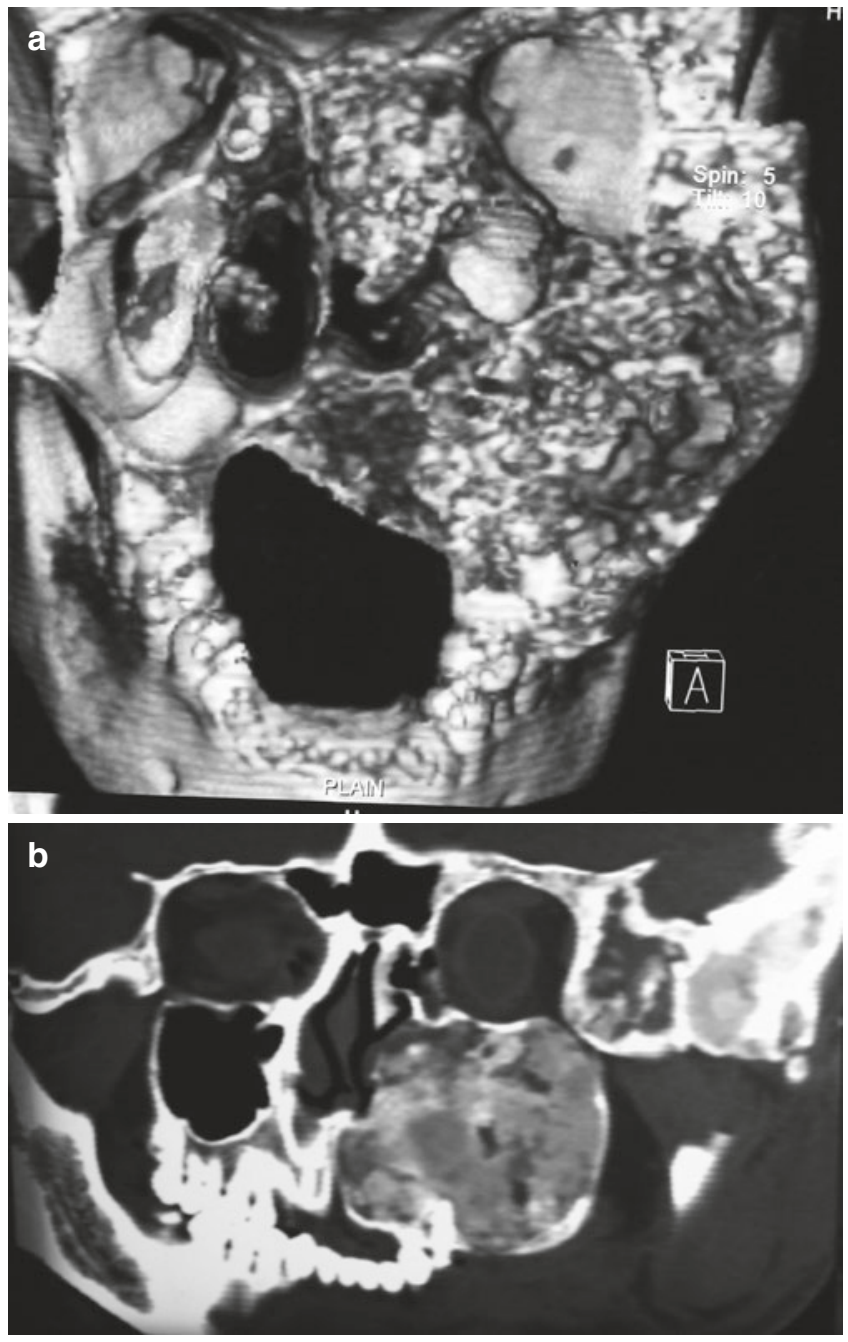

CAssociation of Oral and Maxillofacial Surgeons of India

Fig. 30.7 (a, b) Coronal and panoramic CT views in a 26-year-old man with long-standing swelling of the left side maxilla and cheek bone - the case of JOF-lesion fills the left hand side of the nose and paranasal sinuses 

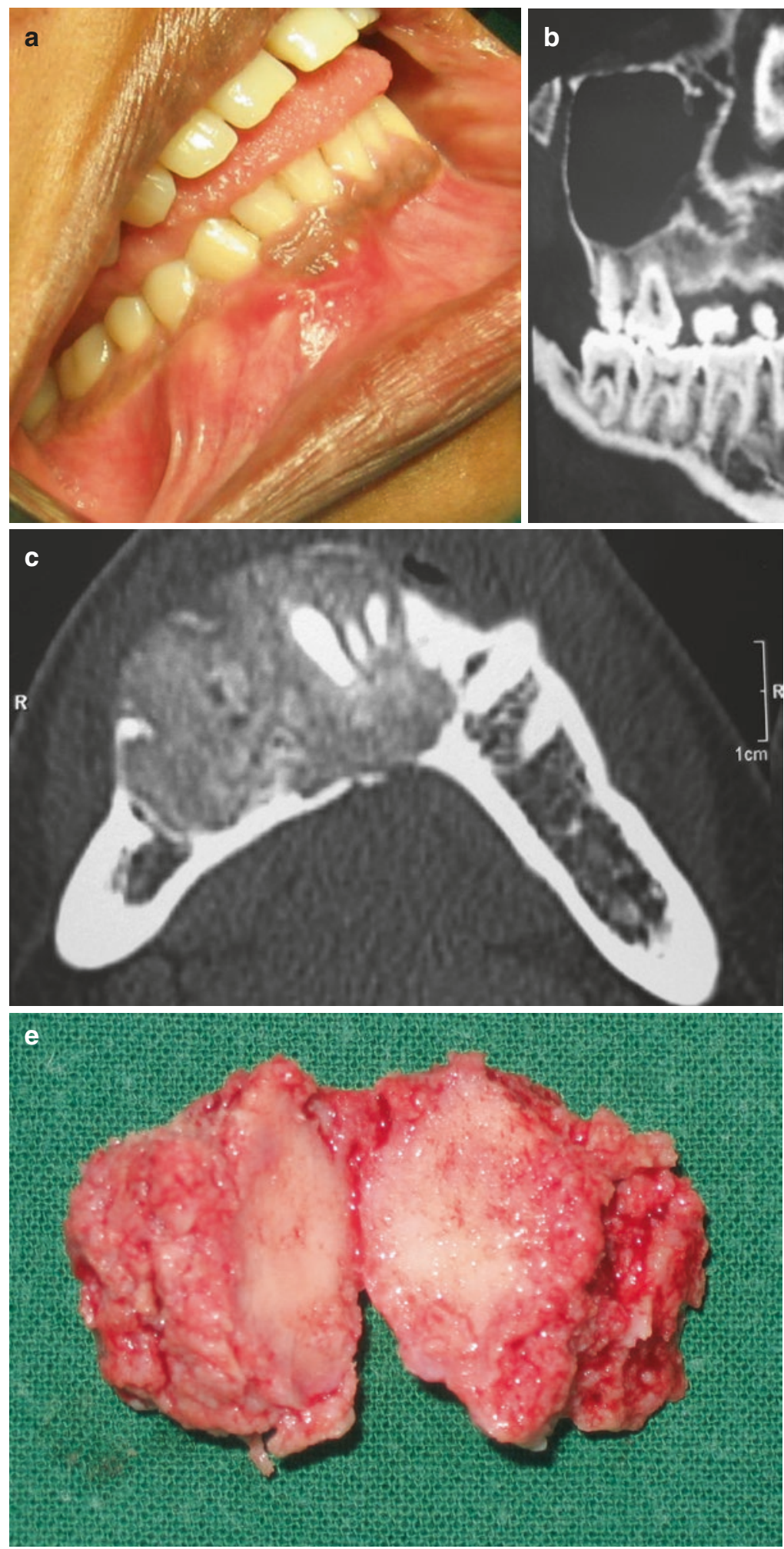

CAssociation of Oral and Maxillofacial Surgeons of India
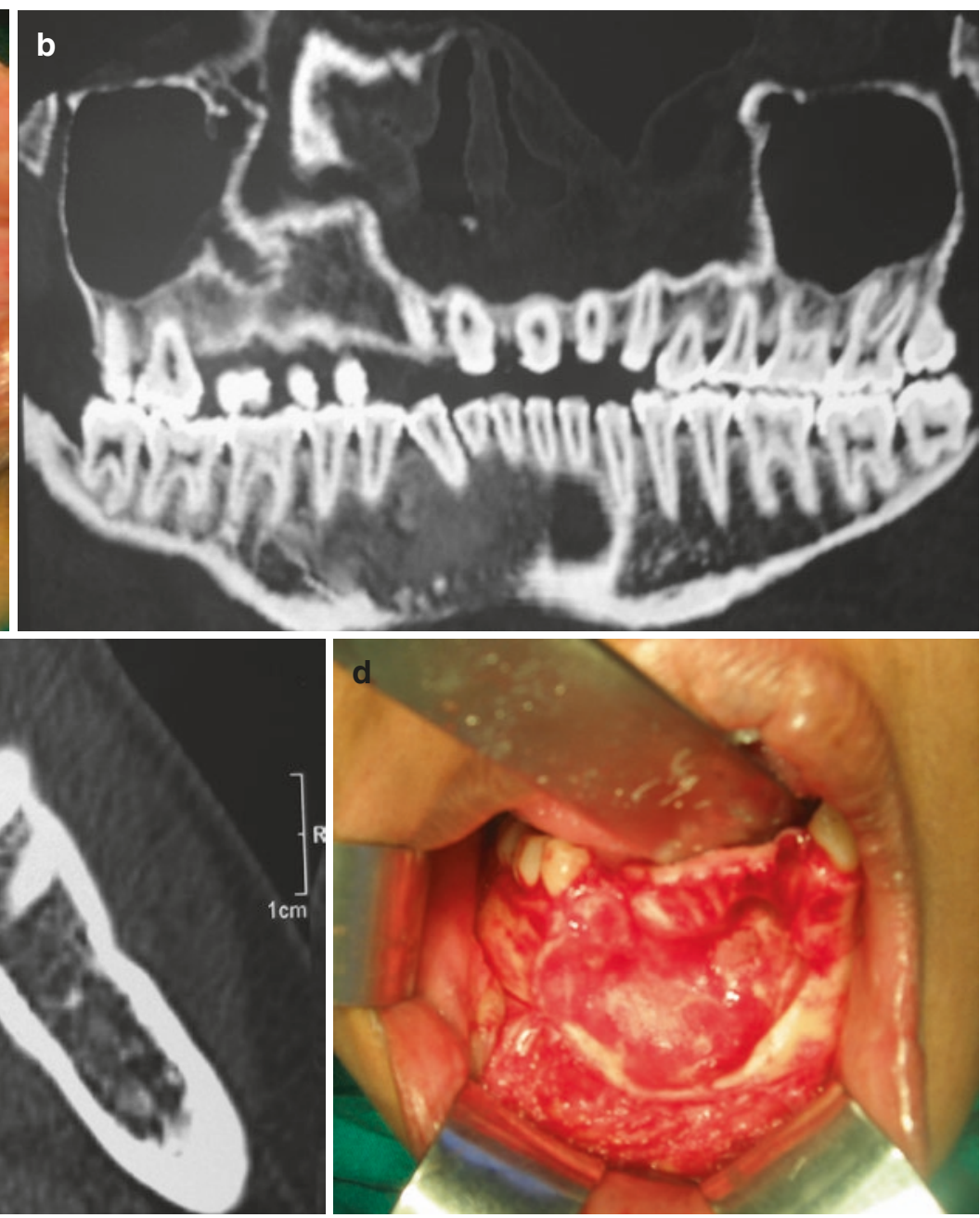


\subsection{Cemento-Osseous Dysplasia (Osseous Dysplasia)}

Osseous dysplasia is a non-neoplastic, commonest, least understood fibro-osseous lesion occurring in tooth-bearing areas of the jaws. The cause of misunderstanding lies at the similarities shared at the clinical and histological levels with other fibro-osseous lesions like fibrous dysplasia and ossifying fibroma and even few neoplasias [28].

Since these lesions lie in close association with the periodontal ligaments of the tooth-bearing segment of the jaws, and histopathologically as well, they bear close similarity with PDL, the strong suspicion of the origin in PDL cannot be ruled out.

Two main types are recognised, based on the clinical and radiological features.

1. Localised and

2. Generalised.

Localised variety includes

(a) Periapical cemento osseous dysplasia (PCOD)

(b) Focal cemento osseous dysplasia (FCOD)

Generalised variety includes

Florid cemento osseous dysplasia

Ideally, these lesions can be identified clinically and radiographically without the need for the biopsy, as the presentation is pathognomonic

Su et al. in 1997 have published a series of 316 cases to distinguish the clinical, radiological and pathological features of the cement osseous dyplasias [29, 30].

\subsection{Periapical Cemento-Osseous Dysplasia}

\subsubsection{Clinical, Radiological and Histological Presentation}

The clinical and radiographic presentation of PCOD is well established. There is a marked predilection for females (14:1) and Afro-Caribbean women [2], and commonly seen in and around the third decade of life, rarely before the age of 20 .

Predominantly involves periapical region of anterior mandible, frequently involving more than one tooth at a time though solitary lesions may be occasionally seen.

These are non-expansile asymptomatic lesions and teeth in association are invariably vital and are discovered accidently when radiographs are taken for other purposes.
Radiographically, maturation of the lesion can be appreciated, when examined at various stages.

Initially, they appear as periapical radiolucencies, which can be easily mistaken for a periapical cyst or a granuloma.

Over a period of time, the mixed radiolucent radiopaque picture may emerge and as the lesion matures further, eventually show dense periapical calcifications at the end stage, which is surrounded by a narrow radiolucent rim. The lesions seldom reach beyond $1-1.5 \mathrm{~cm}$ diameter and growth is selflimiting. The lesions remain separated from the periodontal ligament of the tooth throughout their growth phase.

The histological features are coincidental with radiographic findings and categorised as three stages.

Stage 1: Osteolytic stage/Radiolucent phase

Which shows ample fibrous connective tissue, highly cellular and with numerous small vessels.

Stage 2: Cementoblastic stage/radiolucent radiopaque phase

Various trabecular-woven bone and cementum-like tissues seen.

Stage 3: Mature stage/radiopaque phase

Consolidation of bone- or cementum-like tissue.

\subsection{Focal Cemento Osseous Dysplasia}

For several years, pathologists were aware of the lesions occurring in the mandibular posterior region, often occurring in the tooth-bearing areas and in relation with recently extracted teeth sockets. Waldron recognised them to be, localised fibro-osseous cemental lesions, supposedly reactive in nature. The present understanding of these lesions is hard work of Summerlin and Tomich, besides naming them as Focal cemento osseous dysplasia, they clinically defined them for a better understanding and differentiation from other lesions especially Ossifying Fibroma [31].

\subsubsection{Clinical, Radiological and Histopathological Features}

Focal osseous dysplasia is more commonly seen in AfroCaribbean females. Male to female preponderance is 1:8. Mainly occurs in the 4th to 5th decades of life with 38 years being an average age of occurrence.

The lesion appears as painless, non-expansile, localised condition especially in posterior mandible, both toothbearing areas as well as edentulous mandible where tooth was extracted in the recent past. A clinical, radiographic and 
histopathological differential diagnosis of Focal osseous dysplasia is Ossifying fibroma. Since both are more common in posterior mandible and may appear as radiolucent, mixed or radiopaque, well-circumscribed lesions, the clinical and radiological differentiation can be confusing provided one notices the centrifugal growth pattern of and focal osseous dysplasias barely grow beyond $1.5 \mathrm{~cm}$. Radiographically, focal osseous dysplasias tend to be well defined with slightly irregular borders.

On histological examination, one finds connective tissue stroma comprising of loose collagen fibers, interspersed with irregular shaped cementoid calcifications. Free haemorrhage is noticed throughout, intermixed with collagen background.

\subsection{Florid Cemento-Osseous Dysplasia}

When the lesions, similar in microscopic and radiographic appearance to Focal cemento osseous dysplasia, are found in more than one location in a mandible or in both the quadrants simultaneously, they are identified as Florid cement osseous dysplasia. Radiographs displayed a spectrum of sclerotic and ground-glass opacities limited to alveolar processes but not to root apices [32]. Chronic osteomyelitis may infrequently complicate the disease. These cases appear to represent the most exuberant manifestation of reactive fibro-osseous jaw disease. Many times, these diseases are an incidental finding and patient may be asymptomatic (Figs. 30.9 and 30.10)
Fig. 30.9 OPG of a 73-year-old Asian female, who had $\mathrm{x}$-ray taken for removal of lower right third molar. X-ray shows diffuse florid COD-like lesions
Fig. 30.10 OPG of a 55-year-old Asian female who reported for dental extractions due to pain. Xray reveals florid COD-like lesions in both jaws

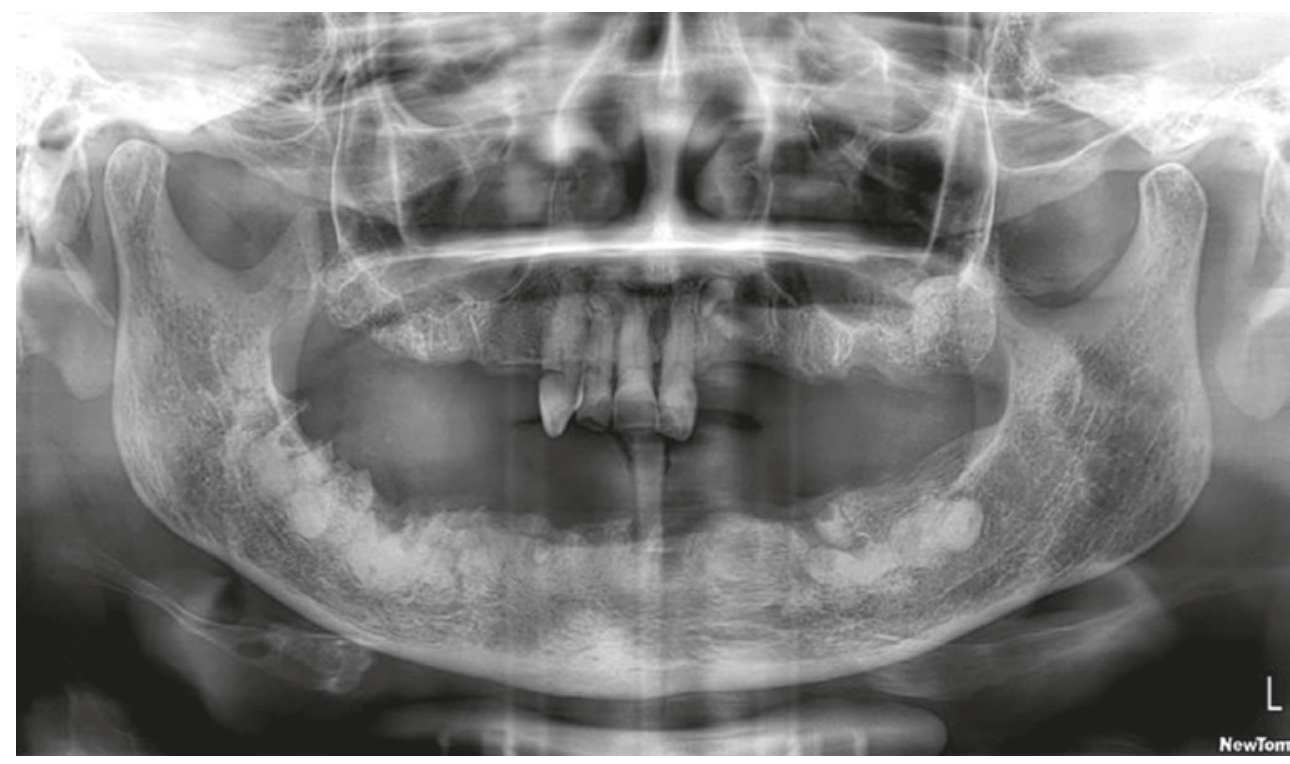

CAssociation of Oral and Maxillofacial Surgeons of India

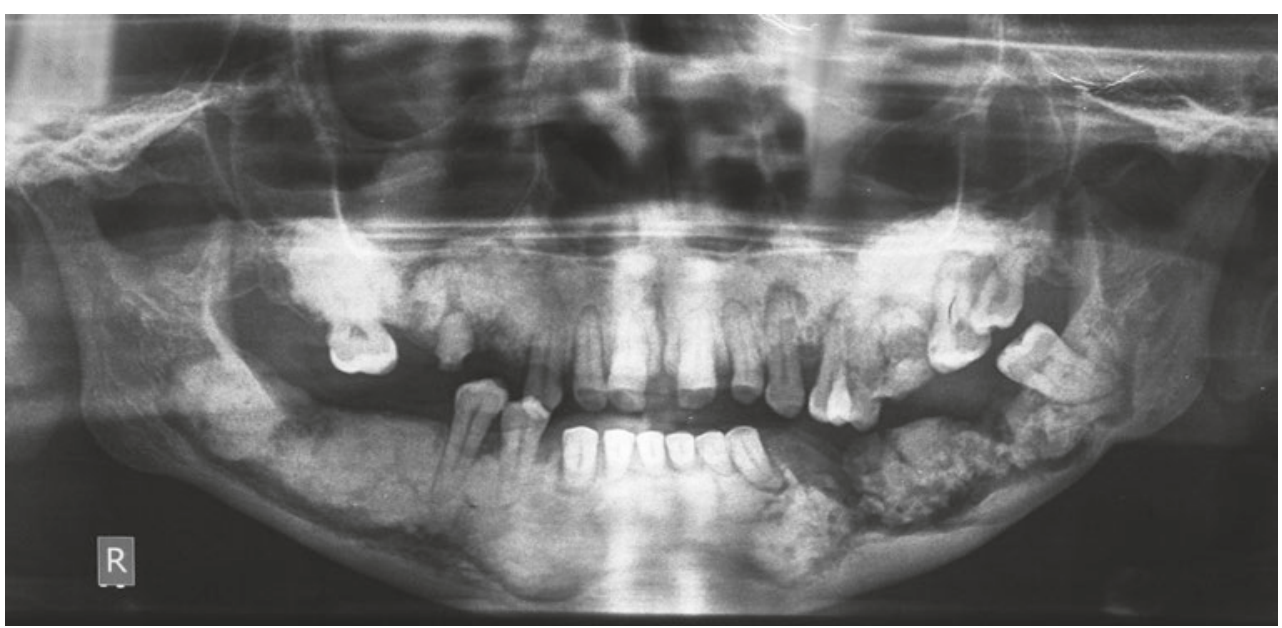

CAssociation of Oral and Maxillofacial Surgeons of India 


\subsubsection{Clinical, Radiological and Histological Features}

Florid cemento osseous dysplasia shows predilection for Afro-Caribbean women in the fourth to fifth decades of life, with a mean age of 42 years. The lesion has a propensity for bilateral symmetrical involvement of mandible. Occasional maxillary involvement is not rare.

The patients are usually edentulous and lesions are usually non-expansible, if cortical expansion is present then it is limited in nature.

The diagnosis of Florid OD is mainly clinical and radiographic, Melrose [32] suggests the involvement of two jaw quadrant is imperative for the diagnosis of Florid COD. Radiographically, the lesion undergoes stages of maturation as seen in the other types of OD, initially, the lesions are mainly radiolucent and with time progressively become first mixed radiolucent radiopaque and then in later stages turn into radiopaque sclerotic masses. Simple bone cyst that appears as sharply defined radiolucent areas may be intermixed with the lesional tissue, is a frequent finding in Florid OD. The most commonest radiographic presentation is of multiple sclerotic lobular opacities mixed ill defined with radiopaque radiolucent masses involving the alveolar process of mandible and maxilla sparing the lower border of the mandible and vertical rami.

Histologically, the lesion has similar features like other two forms of OD. The lesion specimen consists of cellular mesenchymal connective tissue, with numerous spindleshaped fibroblasts and blood vessels. Multiple haemorrhagic sites are a common finding in the connective tissue background along with lamellar-, woven- and cementum-like particles. Depending on the extent of maturation of the lesion, they become more sclerotic and the ratio of fibrous connective tissue to mineralised material decreases.

\subsubsection{Treatment/Management}

The modified osseous tissue is prone to infection, hence any local causes of infection-like periapical pathosis, periodontal disease, ill-fitting dentures can lead to osteomyelitis of the underlying altered bone and fistula and sequestra formation. It is recommended to avoid any surgical intervention for diagnostic purposes, as the diagnosis is generally made on clinical and radiographic presentation. As for the treatment of symptomatic lesions like the presence of underlying osteomyelitis, conservative care in the form of removal of sequestra and prolonged antibiotic therapy is recommended. Extractions are not recommended for the same reason, as the socket heals by replacement with cementum-like tissue, which is mainly avascular.
Surgical intervention in terms of the debulking procedures is only recommended where there is obvious facial deformity resulting in reduced quality of life [33].

\subsection{Conclusion}

FOLs form a diverse wide spectrum of lesions, which are still evolving; in their classifications. Maxillofacial surgeons usually come across intra-oral lesions at various stages and many of them can be managed easily by routine surgical modalities. Certain lesions show aggressive nature and involve mid-face and sino-nasal areas. Such cases will need a multi-disciplinary approach for optimal treatment outcomes. Close interaction with the pathologist and adequate radiological investigations are needed to ascertain the diagnosis in many cases. The lack of clarity in classification and the similar radiological and histological picture of various lesions add to the difficulty in reaching a diagnosis.

Acknowledgments Suvy Manuel for Figures 30.1, 30.2, 30.3, 30.4, 30.5, 30.6, and 30.9

Oommen A Jacob-Figures 30.7, 30.8

Sooraj S- Figure 30.10

\section{References}

1. Eversole R, Su L, ElMofty S. Benign fibro-osseous lesions of the craniofacial complex a review. Head Neck Pathol. 2008;2:177-202.

2. Brannon RB, Fowler CB. Benign fibro-osseous lesions: a review of current concepts. Adv Anat Pathol. 2001;8:126-43.

3. Waldron CA. Fibro osseous lesions of the jaws. J Oral Maxillofac Surg. 1985;43:249-62.

4. Waldron CA. Fibro-osseous lesions of the jaws. J Oral Maxillofac Surg. 1993;51:828-35.

5. Rajpal K, Agarwal R, Chhabra R, Bhattacharya M. Updated classification schemes for fibro-osseous lesions of the oral \& maxillofacial region: a review. IOSR J Dent Med Sci Ver.

6. Srichinthu KK, Yoithapprabhunath TR, Chitturi RT, Yamunadevi A, Potsangbam AD, Singh DN. Fibro osseous lesions-classifications, pathophysiology and importance of radiology: a short review. Int Biol Biomed J. 2016;2:11-20.

7. Slootweg PJ. Maxillofacial fibro-osseous lesions: classification and differential diagnosis. Semin Diagn Pathol. 1996;13:104-12.

8. Barnes L, Eveson JW, Reichart P, Sidransky D. World Health Organization classification of tumours. Pathology and geneticshead and neck tumours. Lyon: IARC; 2005. p. 319-23.

9. Speight P, Carlos R. Maxillofacial fibro-osseous lesions. Curr Diagn Pathol. 2006;12(1):1-10.

10. Waldron CA, Giansanti JS. Benign fibro-osseous lesions of the jaws: a clinical-radiologic-histologic review of sixty-five cases. II. Benign fibro-osseous lesions of periodontal ligament origin. Oral Surg Oral Med Oral Pathol. 1973;35(3):340-50.

11. Hall G. Fibro-osseous lesions of the head and neck. Diagn Histopathol. 2012;18(4):149-58.

12. El-Mofty SK. Fibro-osseous lesions of the craniofacial skeleton: an update. Head Neck Pathol. 2014;8:432-44. 
13. Pereira TDSF, Gomes CC, Brennan PA, Fonseca FP, Gomez RS. Fibrous dysplasia of the jaws: integrating molecular pathogenesis with clinical, radiological, and histopathological features. J Oral Pathol Med. 2019;48:3-9.

14. MacDonald DS. Maxillofacial fibro-osseous lesions. Clin Radiol. 2015;70(1):25-36.

15. Slootweg PJ, Müller H. Differential diagnosis of fibro-osseous jaw lesions. A histological investigation on 30 cases. J Craniomaxillofac Surg. 1990;18(5):210-4.

16. Orten SS, Hanna E. Fibrous dysplasia: biology and indications for surgery. Oper Tech Otolaryngol Head Neck Surg. 1999;10(2):109-12.

17. Chen YR, Noordhoff MS. Treatment of craniomaxillofacial fibrous dysplasia: howearly and how extensive? Plast Reconstr Surg. 1990;86(5):835-42; discussion 843-4.

18. Ricalde P, Horswell BB. Craniofacial fibrous dysplasia of the fronto-orbitalregion: a case series and literature review. J Oral Maxillofac Surg. 2001;59(2):157-67; discussion 167-8.

19. Speight PM, Takata T. New tumour entities in the 4th edition of the World Health Organization classification of head and neck tumours: odontogenic andmaxillofacial bone tumours. Virchows Arch. 2018;472(3):331-9.

20. Zegalie N, Martin L, Speight PM. Ossifying fibromas of thejaws and craniofacial bones. Diagn Histopathol. 2015;2015(21):370-8.

21. Wright JM, Odell EW, Speight PM, Takata T. Odontogenictumors, WHO 2005: where do we go from here? Head Neck Pathol. 2014;8(4):373-82.

22. El-Mofty SK, Nelson B, Toyosawa S. Ossifying fibroma. In: El-Naggar AK, JKC C, Grandis JR, Takata T, Slootweg PJ, editors. WHO classification of head and neck tumours. 4th ed. Lyon: IARC; 2017. p. 251-2.

23. Eversole LR, Leider AS, Nelson K. Ossifying fibroma: a clinicopathologic studyof sixty-four cases. Oral Surg Oral Med Oral Pathol. 1985;60(5):505-11.
24. El-Mofty S. Psammomatoid and trabecular juvenile ossifying fibroma of thecraniofacial skeleton: two distinct clinicopathologic entities. Oral Surg Oral Med Oral Pathol Oral Radiol Endod. 2002;93(3):296-304.

25. Slootweg PJ, Panders AK, Koopmans R, Nikkels PG. Juvenile ossifying fibroma. An analysis of 33 cases with emphasis on histopathological aspects. J Oral Pathol Med. 1994;23(9):385-8.

26. Slootweg PJ, Panders AK, Nikkels PG. Psammomatoid ossifying fibroma of theparanasal sinuses. An extragnathic variant of cementoossifying fibroma. Reportof three cases. J Craniomaxillofac Surg. 1993;21(7):294-7.

27. Titinchi F, Morkel J. Ossifying fibroma: analysis of treatment methods and recurrence patterns. J Oral Maxillofac Surg. 2016;74(12):2409-19.

28. Neville BW, Damm DD, Allen CM, Chi AC. Oral and maxillofacial pathology. 4th ed. St Louis: Saunders; 2016.

29. Su L, Weathers DR, Waldron CA. Distinguishing features of focalcemento-osseous dysplasias and cemento-ossifying fibromas: I. A pathologic spectrum of 316 cases. Oral Surg Oral Med Oral Pathol Oral Radiol Endod. 1997;84(3):301-9.

30. Su L, Weathers DR, Waldron CA. Distinguishing features of focalcemento-osseous dysplasia and cemento-ossifying fibromas. II. A clinical and radiologic spectrum of 316 cases. Oral Surg Oral Med Oral Pathol Oral Radiol Endod. 1997;84(5):540-9.

31. Summerlin DJ, Tomich CE. Focal cemento-osseous dysplasia: a clinicopathologic study of 221 cases. Oral Surg Oral Med Oral Pathol. 1994;78(5):611-20.

32. Melrose RJ, Abrams AM, Mills BG. Florid osseous dysplasia. A clinical-pathologic study of thirty-four cases. Oral Surg Oral Med Oral Pathol. 1976;41(1):62-82.

33. Shah A, Modgill O, et al. Cemento-osseous dysplasia: to treat or not to treat? J Oral Maxillofac Surg. 2016;74(9):e60.

Open Access This chapter is licensed under the terms of the Creative Commons Attribution 4.0 International License (http://creativecommons. org/licenses/by/4.0/), which permits use, sharing, adaptation, distribution and reproduction in any medium or format, as long as you give appropriate credit to the original author(s) and the source, provide a link to the Creative Commons license and indicate if changes were made.

The images or other third party material in this chapter are included in the chapter's Creative Commons license, unless indicated otherwise in a credit line to the material. If material is not included in the chapter's Creative Commons license and your intended use is not permitted by statutory regulation or exceeds the permitted use, you will need to obtain permission directly from the copyright holder. 